\title{
Implementing the integrated model of supervision: A view from the training room
}

Penny Sturt and Bridget Rothwell, Independent Trainers, United Kingdom

\begin{abstract}
The integrated model remains fit for purpose as a framework for supervision which is under significant pressure in an environment of austerity and heightened demand. It will only realise its potential if the power of integration is understood and the influence of context is sufficiently recognised. Successful implementation relies fundamentally on two things: the capacity of both supervisor and supervisee to engage in a relationship, and the availability of systemic support for both that relationship and what it is designed to do.

This viewpoint explains the model, how we use it as trainers and some of the challenges to effective supervision practice we hear being discussed. Social work in the United Kingdom (UK) seems to be grappling with retaining the social when so much focus is on individualised approaches or, as we see them, fragmentary, partial understanding of context. We have summarised this fragmentation as being symbolised by $4 \mathrm{Rs}$, and it remains our view that these elements need to be, and can be, integrated within the supervisory model. In the UK there has been a resurgence in strengths-based approaches, most recently, restorative practice. Arguably, being restorative has always been part of supervisory intention: we think the model supports this quite explicitly. Much emphasis is currently given to the (sometimes misunderstood concept of) resilience of practitioners and we believe the extrinsic elements of this need reiterating. The ability to reflect on the impact practitioners have on others, particularly those using their services, remains key. Finally, the issue of recording needs re-examination.
\end{abstract}

KEYWORDS: Supervision; integrated model; context; relationship; system; reflection; resilience; restorative; recording; capacity

AOTEAROA NEW ZEALAND SOCIAL WORK 31(3), 116-121.

CORRESPONDENCE TO: Penny Sturt

penny_pendrew@btinternet.com
This commentary is from two social work qualified trainers who have developed and delivered learning interventions to support supervisory practice in publicly and voluntary-funded services in health, social work and education over a 20-year period in the UK. The core of our work sits in the supervision model designed by Tony Morrison (2005) and developed in association with Jane Wonnacott (2012). It is important that we acknowledge our roles as Associates of Wonnacott's Consultancy, In-

Trac, which gives us access to conversations with colleagues who have provoked our thinking. We think it is time to emphasise the continuing relevance of the model, and to propose that it is reinforced in two ways: through a reinvigoration of its core elements and principles and by reinforcement of the importance of context through cornerstones of organisational support. The model's colloquial title of " $4 \times 4 \times 4$ " has led to the concept of integration becoming implicit. We suggest that we should return to the original title of the "Integrated Model" to make explicit its overall intended outcome.

This commentary explains the reinforced integrated model, how we use it in the training room and some of the recurring 
challenges to effective supervision practice that we hear being discussed. Social Work in the UK is struggling to retain the social in a system lately focussed on philosophies that emphasise individual responsibilities and solutions. We believe there is a tendency for practice-level individualism to be mirrored in supervisory process and for professionals (and supervision dyads) to be decontextualised. We say organisational context matters and that this aspect of the model, in particular, currently needs additional emphasis. At a time of some emergence of connecting approaches in the UK, we have taken four related contemporary issues to demonstrate the continuing relevance of the model as a parallel process to practice and a mechanism for achieving better contextualisation. First, there has been increasing adoption of strengths-based approaches, most recently, restorative practices. Being restorative has always been a key function of supervision with an intention that supervisees leave restored to their best selves, clear on values, purpose and role. Secondly, the resilience of practitioners is currently much espoused; this is useful if the concept is not (mis) understood as an individual trait. Our third concern, reflection, is much in vogue across the helping professions, with increasing recognition that achieving insights is easier with input from someone else. Finally, we will look at the recurring concern with recording and the consequences of an apparent obsession with information capture.

\section{The integrated model of supervision}

The model is, first and foremost, an integrated one. In this iteration it has 16 components which need to be understood in relation to each other. Each four-part element has coherence and denotes, in turn, interests (four stakeholders); purposes (four functions); process (four aspects of reflection); and foundations (four cornerstones). Each element is necessary but not sufficient. These are depicted in the

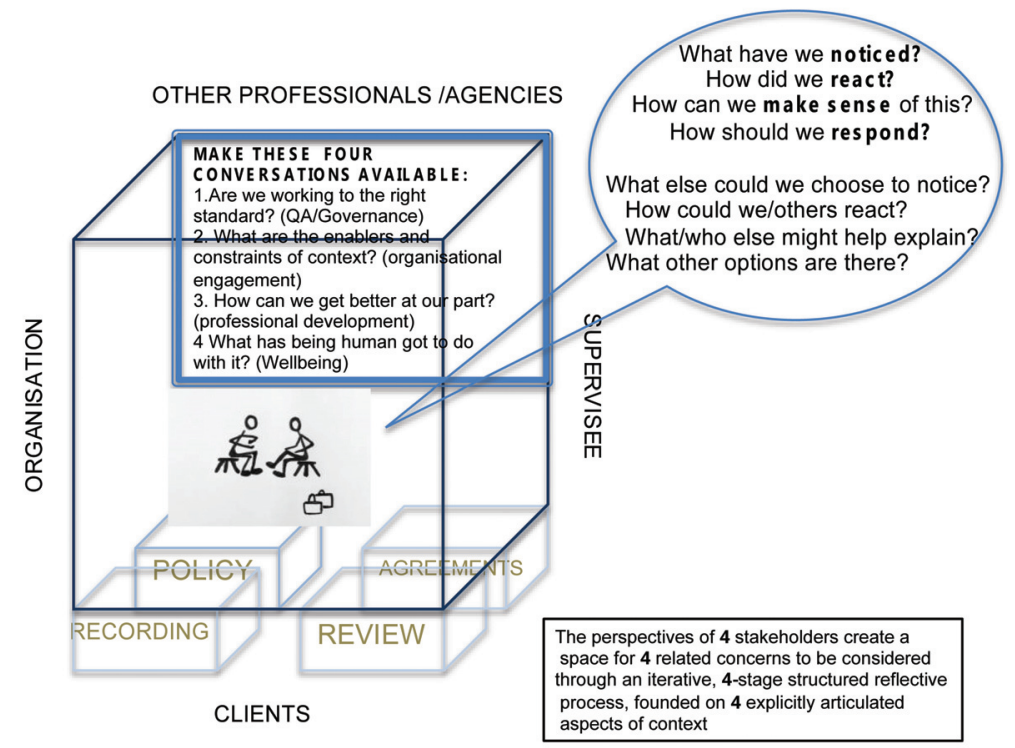

Figure 1. Constructing the integrated model of supervision (Rothwell \& Sturt, nd).

following diagram originally devised by Rothwell and extended, with the addition of the cornerstones, by Sturt. The metaphor of construction is useful in training and gives us a vehicle for building the model in a way that helps participants see the whole. This is not a new model; it is a reinforced version of that designed by Morrison (2005) and extended by, and with, Wonnacott (2012, 2014).

The cuboid structure (four walls) illustrates the need for supervision to continuously hold multiple perspectives in mind: the person using services, the supervisee, the organisation and those in the wider professional and community system. The conception of four stakeholders works most effectively if we recognise their perspectives exist in relation to each other, collaborating and/or competing for space and airtime, for influence and interest in the business of supervision. Beyond this boundaried space, of course, others may influence and be influenced by supervision conversations. We use this to talk about walls closing in (dominating process) or crumbling; to explore walls that speak to make sure that voices (e.g., the children's wall) are included. 
The poster on the wall reminds the supervisory pair of their agreed business: supervision may legitimately address management issues (quality assurance and governance); the joint responsibility of individual and organisation (mediation); development of practice and practitioner; and support their wellbeing. These four functions are held in tension, requiring explicit attention be paid to how both parties authorise each other to participate. Integrating them means that, for example, when a supervisor addresses performance with an eye to unmet standards, she must also be mindful of her human responsibilities to notice and manage the impact of shame or hurt, while also being prepared to debate the supervisee's professional stance. In training we explore the frictions and allegiances between the personal, professional and organisational identities of each individual. Disaggregating the functions, or splitting them between different relationships creates a tendency for splits to appear in the organisational system, unless this is specifically addressed through triangulated agreements.

A key strength of the integrated model is the attention it pays to context through the mediation function ("organisational engagement" in Figure 1). This is reinforced here by the conception of the foundational strength of the cornerstones: the supervision policy determining the organisational expectations and standards, the agreement negotiated between supervisor and supervisee about what will happen in the space, what needs to be recorded of the process and how it will be reviewed. The relationship has to be organisationally mandated and explicitly negotiated, supported and quality assured, otherwise it is in danger of becoming optional; a luxury busy professionals cannot afford or, worse, evidence of their emotional instability or lack of professional knowledge.

The fourth element is a four-stage structure for reflection ("the supervision cycle" Morrison, 2005; Wonnacott, 2012) which helps practitioners share an account of their practice, and themselves in practice, as well as a means by which they can notice their own choices (to perceive, react, consider and respond in certain ways) and so take responsibility.

The whole can be conceptualised as a safetyminded space created for communication about complex practice, a structure to which we can return when the going (inevitably) gets messy, ambiguous and anxiety provoking. Importantly, for this viewpoint discussion, this supervision space is not freefloating and context free. It is founded upon organisational mechanisms and assumptions which significantly influence its capacity to work effectively with the four contemporary concerns we have selected to illustrate its relevance.

The idea that supervision is concerned with restoration is not new (Kadushin, 1992; Morrison, 2005). Restorative practice (Wachtel, 2016) is fundamentally focussed on the restoration of social discipline in which both the helped and the helper are mutually accountable. The experience of the helped is a source of legitimate and fundamental information. While bringing their expertise and authority to bear, the helper does not presume to know better. This sets a direction of travel which is collaborative and such encounters demand a high level of connection and engagement. This is most effective when there is well established social capital, "a network of relationships [built on...] trust, mutual understanding, shared values and behaviour" (Wachtel, 2016, p. 1). Restorative practice embraces the challenge and complexity of human co-existence and conflict of needs; it presumes differences of opinion and the possibility of progress.

In the training room it is clear that many supervisors want to offer supervision that both supports and mirrors this kind of practice, but that very basic barriers exist, arguably because of the erosion of social capital in organisations subjected to a long period of austerity and the accompanying 
ideology of individualism. This has impacted in fundamental ways on the experiences supervisors and supervisees have at work, just one of which is the loss of predictable and physically boundaried (i.e., nontransparent walls) spaces in which to carry out sensitive and demanding supervision. The "taken-for-granteds" of where, when and how supervisory encounters might take place have been disrupted, undermining the reliability of connecting in appropriately calibrated (trusting, mutually understanding) ways. The offsiting of supervision to other venues (cafes, homes, or online) contributes to disconnects between supervision and the organisational community. These shifts are accompanied and amplified by flexible, mobile practices (Ferguson, 2008), and increasingly porous organisational boundaries enabled by technological innovation (Disney et al., 2019), reinforcing the need for a confidential, safe space which holds and contains practice and practitioners.

Furthermore, central to restorative practice is an understanding that the expression of affect is what helps us function best (Wachtel, 2016). Inhibition of practitioners' opportunities to safely process the impacts on them of the danger, distress, anger, loss, grief and confusion of families takes its toll. Far from being restored back to functional and sensitive practice, the disconnect is reinforced as demands continue to be placed on them. Supervisors talk about being instructed to "just tell them," to consider "performance management" processes in response to deterioration in both wellbeing and practice, to question practitioners' capability and sometimes the "accuracy" of their accounts.

The integrated model cannot change this reality. But it can make explicit the decontextualisation of supervision as it becomes compromised or off-sited. The model calls all stakeholders into view, visually restoring the organisation's interest in, and noting its influence over, the supervisory conversation. From this position the supervisory pair can attend deliberately to the needs (and demands) of all stakeholders. This is not equal, but seeks to be equitable, and to articulate the prioritisation of some needs over others. So a (committed, passionate) supervisee is not expected to repeatedly self-sacrifice in the service of children while their organisation fails to manage the flow of demand, and others draw defensive boundaries around their contribution. They may choose to go the extra mile, but in the understanding that this will be recognised in the system and a balance restored. The balance of functions is invoked: standards (against legislated and policy requirements) are set, and the means to achieving them is explicitly understood to depend on a combination of the organisation's capacity to resource the work, the practitioner's capability, and the family's willingness. The practitioner's capability is itself a function of their current capacity to use structured reflection to notice the child and their circumstances, to engage emotionally, to grapple with meaning and so to respond effectively. Articulating this through supervisory exchange restores the balance of responsibility; restores the practitioner's relationship with themselves (self-esteem and self-efficacy) and others (secure base) and so enhances their resilience, and provides the means to identify ways of refining and improving the collective experience for everyone.

Supervisors describe, however, a system in which one stakeholder's demands (usually the organisation(s)' dominates to the exclusion of others too often and too much; where one function trumps others (usually management), and where incomplete or unbalanced narratives emerge, privileging one part of the process (usually doing) over others (usually feeling and thinking). The dominance of performance management culture has left practitioners wary of organisational responses to their needs, and reluctant or unable to discuss the impact of the work on them and, more importantly, to 
accurately perceive the circumstances of the people they are trying to help.

Which has taken us to reflection. Supervisors tell us they are expected to provide opportunities for practitioners to reflect for a variety of reasons: processing emotional impact; developing thoughtful analysis; reaching defensible decisions; and improving outcomes for children. Alongside this, many supervisors must meet organisational demands to attend to every case held by practitioners in every supervision. Both the practical and emotional challenges are obvious. Somehow supervisors must convey a wish to develop autonomous professionalism while simultaneously undermining the practitioner's experience of being trusted. Our training room conversations suggest that too many organisations are complicit in patterns of presenteeism resulting from a focus on targets (usually time-based) often reinforced through naming and shaming rituals. Little wonder that supervision in such systems becomes focussed on quantifiable and tangible products. These are not new observations (see Munro, 2011) but they are depressingly current and recurring. What goes on in supervision is a reflection of the priorities of a wider context. Until the priorities (as reflected in what gets measured and rewarded) change, reflective process in supervision will remain limited or absent.

When the supervision cycle is practised, developing critical, reflective thinking, and facilitating opportunities that help practitioners to learn how to think about their work, they grow the skills of managing reflection by themselves; what Ferguson (2018, after Casement, 1985) labels "the internal supervisor." This might allow supervision to progress to a deeper, more reflexive, double loop (Argyris, 1991) process. The felt security that comes from these opportunities means that staff may manage their anxieties more effectively and so require fewer unplanned interactions. Over time, staff will internalise their expectation of contextual support and so develop trust that there is organisational commitment to maintaining their thinking capacity. While supervisors leave training enthused, our experience is that transfer and maintenance in the workplace is limited. While noticeable enthusiasm for group supervision with all the benefits it may bring is emerging, there is little evidence that organisations support and enable supervisors and staff to experiment and explore methods.

Supervision is about chains of connection through relationship; from organisation to supervisor to supervisee to child and back again. Relationships strengthen resilience (Grotberg 1995). Resilience, a slippery (and misused) phenomenon, reflects a person's positive adaptation despite experiences of adversity (Riley \& Masten, 2005) and incorporates characteristics of both the individual and their environment. An individual's capacity to be resilient depends on being able to draw on both sources (Grant \& Kinman, 2014). Supervisors feel responsible for staff wellbeing and are keen to fulfil their role in developing and sustaining resilience in their team members. But often, resilience is reduced to a measure of individual hardiness, the capacity to survive rather than the outcome of the complex interplay between the experience of being offered a secure base (the availability of people who genuinely bear their interests in mind,) and the capacity to draw on established beliefs about self-worth and selfefficacy.

Resilience has personal, professional and organisational aspects to it. In order to maintain and sustain resilience, practitioners need relationships from which they can draw strength. If organisations take no responsibility for enabling such relationships they run the risk that practitioners themselves become depleted, with diminished capacity to care and be curious about others. Being able to rely on relational support strengthens staff, team and organisational self-esteem, 
and builds capacity sufficiently that staff respond positively to tasks they are asked to do. This happens because they know themselves to be competent from the nature of the relational contact, especially if that is explicitly negotiated as forming part of the emotional labour taking place in the space of supervision.

Our final brief thoughts are about recording supervision. This discussion mirrors those about records for those who use services and is contextualised by the common organisational demand for evidence that every case is discussed at every supervisory meeting. The experience of supervisors as technologically hamstrung data inputters makes it a common concern in training. Both supervisees and supervisors talk of turned backs and nonsensical, contradictory truisms about what recording reveals - that it gives an ultimate and accurate account that, if it is not recorded, it did not happen. The performance measure rarely clarifies issues of quality. We explore in training the need to negotiate and co-produce the recording, developing and deepening the relationship between supervisor and supervisee and so building the necessary trust for safe uncertainty about what is written. Accurately recording the nuances of this process so that it truly reflects the quality of the relationships, as well as stands up to external scrutiny, research or audit of the emerging recorded dialogue across the organisation and inspectorate, has proved challenging and remains disputed (Wilkins, Jones, \& Westlake, 2018). The integrated model provides a set of principles: be explicit about perspectives; be clear about purpose; be explicit about exercising choice in what we see, feel, think and do. Once again, context matters: what is it that organisations-and regulators-want? What is it they can tolerate as evidence of thoughtful process?

These challenges convince us that the integrated model of supervision, when fully understood, continues to offer a framework to support helping professionals to think critically, experience containment and belonging and so to restore them to positions where they can bear witness to other people's lives.

\section{References}

Argyris, C. (1991). Teaching smart people how to learn. Harvard Business Review, May-June, 99-109.

Disney, T., Warwick, L., Ferguson, H., Leigh, J., Cooner, T. S., Beddoe, L., . . . Osborne, T. (2019). "Isn't it funny the children that are further away we don't think about as much?": Using GPS to explore the mobilities and geographies of social work and child protection practice. Children and Youth Services Review, 100, 39-49. doi:https:beddbedd//doi.org/10.1016/j. childyouth.2019.02.029

Ferguson, H. (2008). Liquid social work: Welfare interventions as mobile practices. British Journal of Social Work, 38(3), 561-579.

Ferguson, H. (2018). How social workers reflect in action and when and why they don't: The possibilities and limits to reflective practice in social work. Social Work Education, 37(4), 415-427.

Grant, L., \& Kinman, G. (Eds.). (2014). Developing resilience for social work practice. London, UK: Palgrave Macmillan.

Grotberg, E. (1995). A guide to promoting resilience in children: Strengthening the human spirit. The Hague, Netherlands: Bernard Van Leer Foundation.

Kadushin, A. (1992). Supervision in Social Work. New York, NY: Columbia University Press.

Morrison, T. (2005). Staff supervision in social care: Making a real difference to staff and service users. Brighton, UK: Pavilion Publishing and Media.

Munro, E. (2011). The Munro review of child protection: Final report. A child centred system. London, UK: Department for Education.

Riley, J., \& Masten, A. (2005). Resilience in context. In R. Peters, B. Leadbeater, \& R. McMahon (Eds.), Resilience in children, families and communities: Linking context to practice and policy (pp. 13-25). New York, NY: Kluwer Academic/Plenum Publishers.

Wachtel, D. (2016). Defining restorative IIRP. Retrieved from https://iirp.edu/images/pdf/Defining-Restorative_Nov2016.pdf

Wilkins, D., Jones, R., \& Westlake, D. (2018). The activity does not archive well: Comparing audio and written records of supervision case discussions in Children's Services. Journal of Children's Services, 13(3/4), 93-109. doi:10.1108/JCS-03-2018-0005

Wonnacott, J. (2012). Mastering social work supervision. London, UK: Jessica Kingsley Publishers.

Wonnacott, J. (2014). Developing and supporting effective staff supervision. Brighton, UK: Pavilion Publishing and Media. 